\title{
Lack of Apaf-1 expression confers resistance to cytochrome $c$-driven apoptosis in cardiomyocytes
}

\author{
D Sanchis ${ }^{1}$, M Mayorga $^{2}$, M Ballester ${ }^{3}$, JX Comella ${ }^{*, 2}$ \\ ${ }^{1}$ Departament de Recerca, Hospital Universitari Arnau de Vilanova, Lleida, \\ Spain; \\ 2 Departament de Ciències Mèdiques Bàsiques, Facultat de Medicina, \\ Universitat de Lleida, Lleida, Spain; \\ ${ }^{3}$ Departament de Medicina, Facultat de Medicina, Universitat de Lleida, Lleida, \\ Spain \\ * Corresponding author: JX Comella, Departament de Ciències Mèdiques \\ Bàsiques, Facultat de Medicina, Av. Rovira Roure, 4425198 Lleida, Spain. \\ Tel: + 349737024 14; Fax: + 349737024 38; \\ E-mail: joan.comella@cmb.udl.es
}

Received 18.12.02; revised 03.3.03; accepted 02.4.03

Edited by M Piacentini

\begin{abstract}
Apoptosis plays a role in cardiomyocyte death in several cardiovascular disorders. Here, we show that primary postnatal cardiomyocytes did not die upon activation of the intrinsic (cytochrome c-dependent) apoptotic pathway. Release of cytochrome $c$ from mitochondria to the cytosol occurred, but did not activate the effector phase of apoptosis. Myocardial cells did not express apoptotic protease-activating factor-1 (Apaf-1), the allosteric activator of caspase-9 acting downstream of cytochrome $c$ release. Forced expression of Apaf-1 restored the competence to complete the cytochrome $c$-induced apoptotic program and this effect was prevented by overexpression of $\mathrm{Bcl}-\mathrm{X}_{\mathrm{L}}$. However, cardiomyocytes were able to enter the apoptotic program when it was initiated by activation of death receptors, as observed during serum deprivation and metabolic inhibition. Our results indicate that regulation of Apaf-1 expression may be a new regulatory mechanism developed in postmitotic cells in order to prevent irreversible commitment to die after release of cytochrome $c$. Cell Death and Differentiation (2003) 10, 977-986. doi:10.1038/ sj.cdd. 4401267
\end{abstract}

Keywords: apoptosis; cytochrome $c$; Apaf-1; caspase; cardiomyocyte; endothelial cell

Abbreviations: Ac-DEVD-afc, acetyl-Asp[OMe]-Glu[OMe]-ValAsp[OMe]-7-amino-4-trifluoromethylcoumarin; PBS, phosphatebuffered saline; PFA, paraformaldehyde; TUNEL, TdT-mediated dUTP nick end-labeling; z-DEVD-fmk, benzyloxycarbonylAsp[OMe]-Glu[OMe]-Val-Asp[OMe]-fluoromethylketone; z-IETD-fmk, benzyloxycarbonyl-Ile-Glu[OMe]-Thr-Asp[OMe]fluoromethylketone; z-VAD-fmk, benzyloxycarbonyl-Val-Ala- As$\mathrm{p}[\mathrm{OMe}]$-fluoromethylketone

\section{Introduction}

Cardiomyocyte apoptosis occurs during the course of certain cardiovascular diseases such as cardiomyopathy, hypertension and during rejection. ${ }^{1-4}$ Postnatal cardiomyocytes are terminally differentiated cells that are not able to divide at a rate allowing for the replacement of dead cells. ${ }^{5}$ Ongoing cellular loss in these conditions could be a determining factor in the progression to heart failure, ${ }^{6}$ although the relative contribution of the apoptotic pathways has not been fully elucidated. Furthermore, it has been reported that myocardial apoptosis could be incomplete in the failing human heart, ${ }^{7}$ and that cleavage of executioner caspases is low in cardiomyocytes compared with surrounding endothelium in the rat heart upon ischemia/reperfusion-induced injury. ${ }^{8}$ These data suggest the existence of unknown antiapoptotic mechanisms in cardiomyocytes.

In mammals, caspase-dependent programmed cell death occurs through at least two main pathways. In the extrinsic pathway, activation of death receptors located on the cytosolic membrane triggers an intracellular signaling cascade involving the activation of caspase-8, which in turn cleaves and activates executioner caspases, ${ }^{9}$ inducing disruption of cell homeostasis, ${ }^{10}$ internucleosomal DNA fragmentation ${ }^{11}$ and cell death. On the other hand, in the intrinsic (mitochondrial) pathway, mitochondrial proteins such as cytochrome $c$ and SMAC/DIABLO are released into the cytoplasm under several stress situations. In the cytosol, cytochrome $c$ and ATP catalyze the oligomerization of apoptotic protease-activating factor-1 (Apaf-1), which recruits and activates caspase-9 inducing the processing and activation of executioner caspases. ${ }^{12,13}$

Our attempts to induce programmed cell death in rat neonatal cardiomyocytes by treatment with staurosporine (STS), a wide range apoptosis-inducing agent, which triggers the release of cytochrome $c$ into the cytosol by a mechanism involving Bak and Bax, ${ }^{14,15}$ revealed that the execution phase of apoptosis did not occur despite cytochrome $c$ translocation. We investigated this phenomenon and characterized the downstream regulation of apoptosis in this setting. Our findings revealed the absence of Apaf-1 expression, which prevented cytochrome $c$ release from activating executioner caspases. In fact, induction of Apaf-1 expression leads to nuclear fragmentation of cardiomyocytes after STS treatment and this effect was blocked by coexpression of antiapoptotic Bcl-2 family member $\mathrm{Bcl}-\mathrm{X}_{\mathrm{L}}$, which is reported to prevent cytochrome $c$ release. In contrast, serum deprivation and glucose metabolism inhibition, which has been recently described to induce apoptosis dependent on death receptor activation in cardiomyocytes, ${ }^{16}$ triggered the complete apoptotic program.

\section{Results}

\section{Cardiomyocytes are resistant to STS-induced cell} death

STS-induced cell death in myocytes was 2. 5-fold lower than in vascular endothelium at STS concentrations ranging from 
0.01 to $1.0 \mu \mathrm{mol} / \mathrm{l}$ after $24 \mathrm{~h}$ of treatment (Figure 1a). Myocardial resistance to STS-induced toxicity did not diminish with an increasing time of exposure (Figure 1b), whereas cell death reached $100 \%$ in endothelium after $48 \mathrm{~h}$ (Figure 1b). Cytoplasm condensation, an early feature of apoptosis, was induced by STS both in rat cardiomyocytes and in endothelial cells (Figure 1c), although the degree of cell shrinkage was remarkably low in cardiomyocytes. Cell shrinking was not prevented by pretreatment with $100 \mu \mathrm{mol} / /$ of the broad-spectrum caspase inhibitor benzyloxycarbonyl-Val-Ala-Asp[Ome]fluoromethylketone (z-VAD.fmk) (data not shown). Furthermore, after treatment with $1 \mu \mathrm{mol} / \mathrm{l}$ STS for $24 \mathrm{~h}$, some myocardial cells kept on beating although at lower rates than control cells $(60 \pm 10$ versus $220 \pm 5$ beats/min respectively, $P<0.001$, Student's $t$-test). In addition, cardiomyocytes treated for $24 \mathrm{~h}$ with $1 \mu \mathrm{mol} / \mathrm{l}$ STS recovered the sarcomer ultrastructure and its beating activity after withdrawal of the drug (Figure 2). These results indicate that postnatal differentiated cardiomyocytes were resistant to STS-induced cytotoxicity.
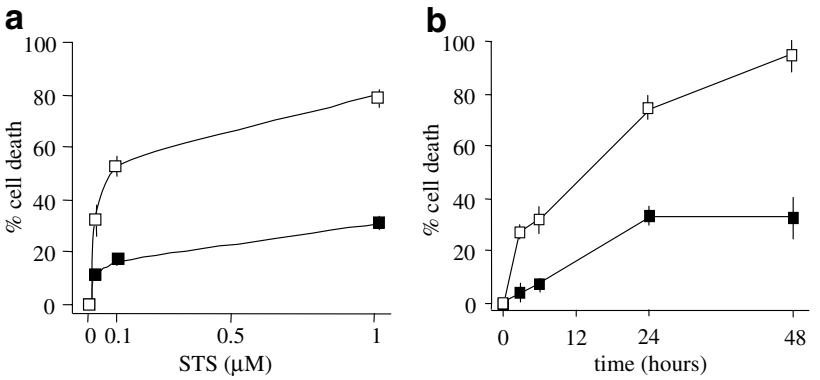

C

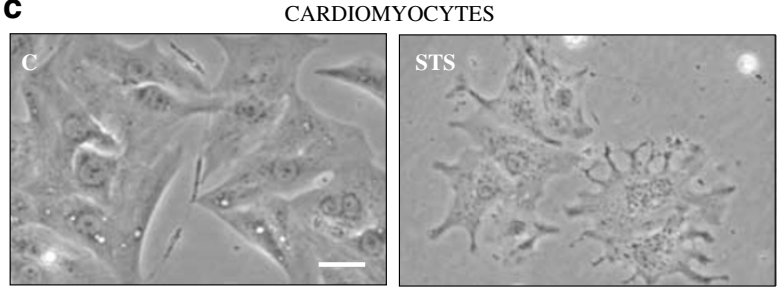

ENDOTHELIUM
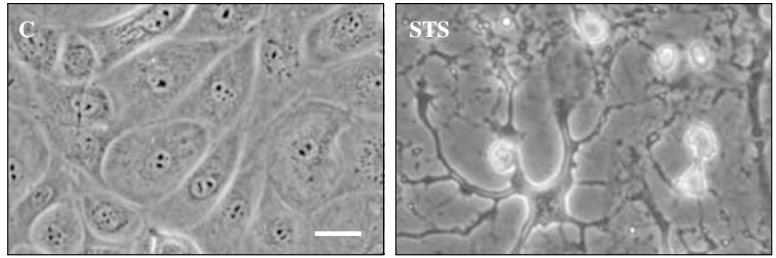

Figure 1 Primary neonatal cardiomyocytes are more resistant than vascular endothelial cells to STS-induced changes in cell morphology and cell viability. (a) Concentration-dependent effects of STS on cell viability. Cell death was measured using the trypan-blue exclusion assay and is expressed as percentage of cell death versus untreated cultures at time zero. (b) Time course of cell death at $1 \mu \mathrm{mol} / / \mathrm{STS}$. Values in (a) and (b) are means + S.E.M. of three independent experiments performed in duplicate (white squares, endothelium; black squares, cardiomyocytes). (c) Phase-contrast photomicrographs of control cells (C) and cells cultured $24 \mathrm{~h}$ in the presence of $1 \mu \mathrm{mol} / \mathrm{l}$ STS (STS). Bar, $50 \mu \mathrm{m}$

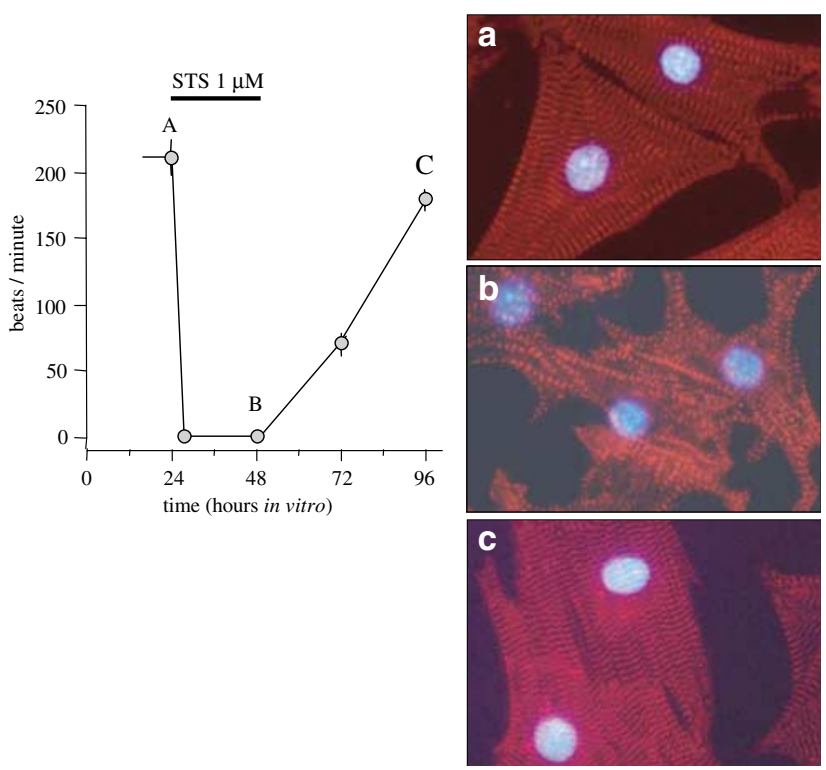

Figure 2 Cardiomyocytes recover morphology and function after withdrawal of STS. Beating activity was measured in primary cultures of cardiomyocytes before STS addition to the culture medium at $1 \mu \mathrm{mol} / \mathrm{l}$, during STS exposure (top bar $=24 \mathrm{~h}$ ), and 24 and $48 \mathrm{~h}$ after withdrawal of the drug. Beating activity in every plate was calculated as the mean of beats per minute in five representative regions of the same plate and data in the graphic are expressed as mean \pm S.E.M. of three independent experiments. Fluorescence photomicrographs are representative images of myocardial cells stained for cardiac-specific $\alpha$-actinin (red) and DNA (blue) at the points denoted in the time course with the same cap

\section{Cardiomyocytes do not attain chromatin fragmentation after STS treatment}

To explore whether STS induced apoptosis in cardiovascular cells, we first tested DNA damage as a marker of apoptotic cell death. In situ staining of the chromatin with bis-benzimide dye demonstrated that, in contrast to endothelial cells, cardiomyocyte nuclei did not fragment after treatment with $1 \mu \mathrm{mol} / \mathrm{I}$ STS for $24 \mathrm{~h}$ (Figure 3a). To assess DNA cleavage, we performed agarose-gel electrophoresis of whole-DNA extracts from control cells and cells treated with $1 \mu \mathrm{mol} / \mathrm{l}$ for $24 \mathrm{~h}$. Low molecular weight DNA fragmentation (laddering) was detected in STS-treated endothelium, but not in cardiomyocyte cultures (Figure 3b). Furthermore, in cardiac cultures, nuclear fragmentation did not occur in cardiomyocytes but only in contaminant nonmyocardial cells, as demonstrated by immunocytochemical detection of cardiomyocyte-specific $\alpha$ actinin and nuclear staining in control and STS-treated cultures (Figure $3 \mathrm{c}$ ). These results indicated the ability of cardiomyocytes to arrest the caspase-dependent apoptotic program before entering the execution phase.

\section{STS triggers cytosolic translocation of cytochrome $c$ in cardiomyocytes but fails to activate downstream apoptotic events}

STS-induced apoptotic cell death is mainly driven by the mitochondrial pathway. ${ }^{15}$ Cytochrome $c$-defective cells are known to become resistant to STS-induced cell death, but 
a
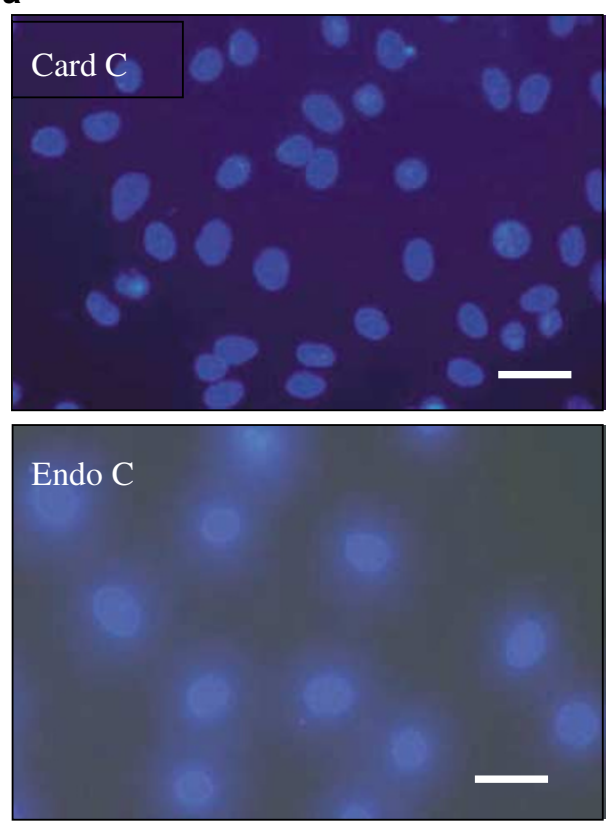

b

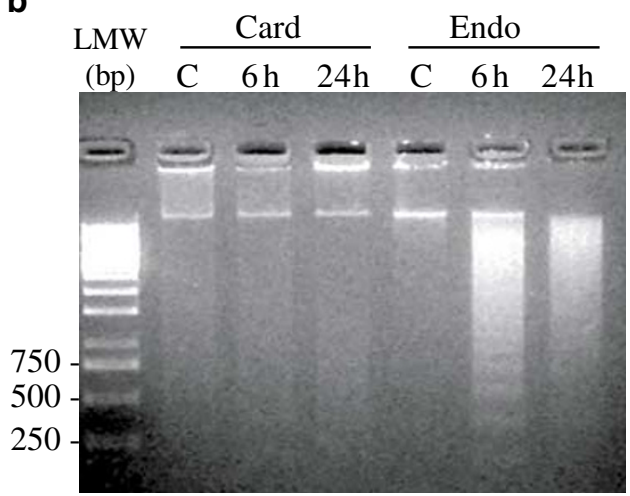

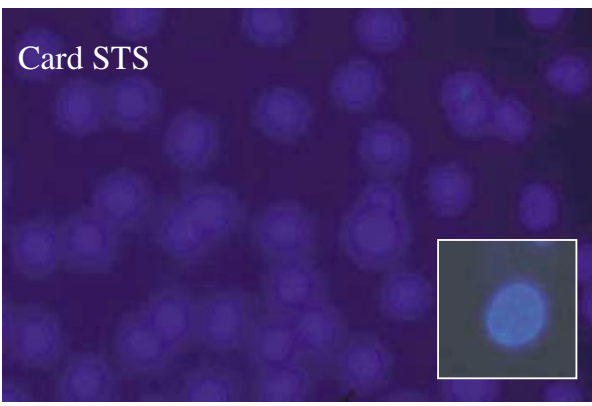

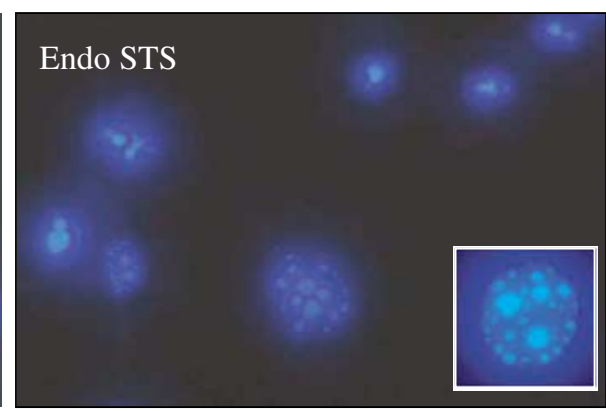

C

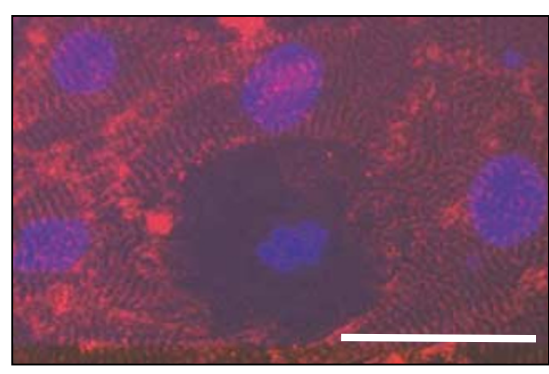

Figure 3 STS does not induce nuclear fragmentation in primary neonatal cardiomyocytes. (a) Fluorescence photomicrographs of cell nuclei stained with bis-benzimide in cardiac (Card) and endothelial (Endo) cultures untreated (c) or after $24 \mathrm{~h}$ of $1 \mu \mathrm{mol} / \mathrm{I}$ STS treatment (STS). (b) DNA low molecular weight fragmentation resolved by $1 \%$ agarose-gel electrophoresis and visualized by ethidium bromide staining of DNA extracts from cardiomyocytes (Card) and endothelium (Endo) untreated (c) and treated for 6 and $24 \mathrm{~h}$ with $1 \mu \mathrm{mol} / / \mathrm{STS}$. (C) Fluorescence photomicrograph of a cardiomyocyte culture treated for $24 \mathrm{~h}$ with $1 \mu$ mol/ $\mathrm{STS}$. Myocardial $\alpha$-actinin is stained in red and nuclei are stained with bis-benzimide (blue). Bar, $50 \mu \mathrm{m}$

remain sensitive to death receptor stimulation. ${ }^{17}$ It is also known that caspase-8-deficient cells are resistant to death receptor-induced apoptosis, but are still susceptible to STSinduced cell death. ${ }^{18}$ STS was found to initiate morphological changes, characteristic of apoptotic death, both in cardiomyocytes and endothelial cells, but only the latter were able to follow the apoptotic program. To provide insight into the molecular pathways involved in the relative cardiomyocyte resistance to STS-triggered apoptosis, we first investigated to determine whether it was able to induce cytochrome $c$ release into the cytosol. After $6 \mathrm{~h}$ of STS treatment, cytochrome $c$ appeared in cytosolic extracts of endothelium and cardiomyocytes (Figure $4 \mathrm{a}$ ), increasing at $24 \mathrm{~h}$. The time-dependent increase in cytosolic cytochrome $c$ correlated with a decrease of the cytochrome $c$ in the particulated fraction (Figure $4 a$, bottom panel). The possible role of antiapoptotic Bcl-2 family members in cardiomyocyte resistance to STS was ruled out, as these proteins mainly act by preventing cytochrome $c$ release from mitochondria. ${ }^{19}$

Caspase-3 activity has been reported in cardiomyocyte apoptosis. ${ }^{20,21}$ We analyzed caspase-3 activity by immunodetecting its active, processed form of approximately $20 \mathrm{kDa}$, by analyzing the cleavage of one of its specific substrates, fodrin, ${ }^{22}$ and by measuring its enzymatic activity in extracts from control and STS-treated cells. STS treatment of endothelium induced a time-dependent cleavage of caspase- 3 and fodrin, which is itself cleaved by caspase-3 rendering a fragment of $120 \mathrm{kDa}$. These effects were maximal after $24 \mathrm{~h}$ (Figure $4 \mathrm{~b}$ ). The time course of caspase-3 and fodrin cleavage correlated with that of DNA laddering and endothelial cell death. However, this was not the case for cardiomyocytes. STS treatment of endothelium induced 
a

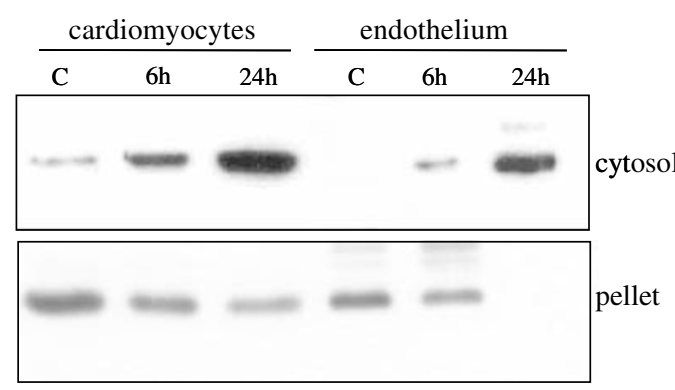

b

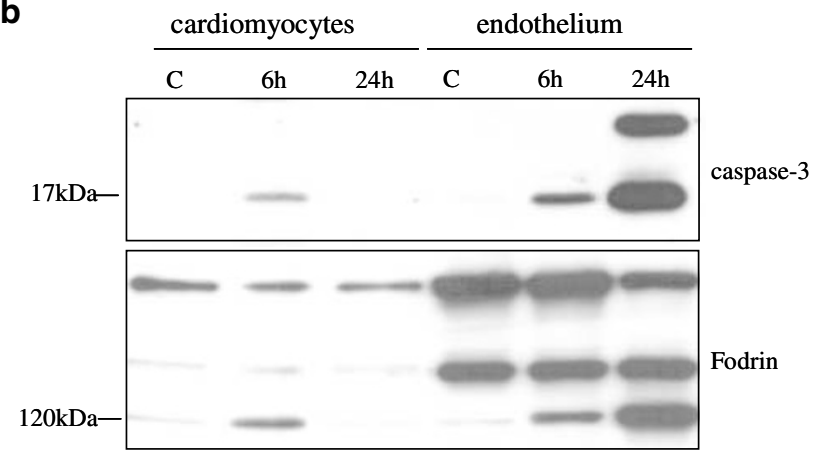

C

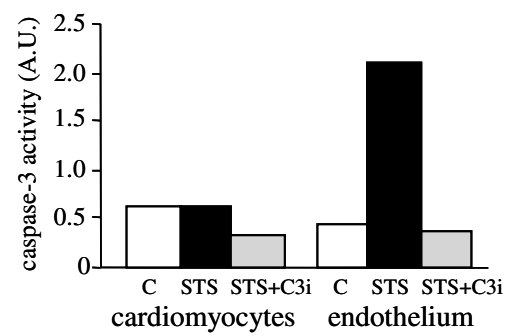

Figure 4 STS induces cytochrome $c$ release to the cytosol in primary neonatal cardiomyocytes, but not caspase-3 activation. (a) Cytochrome $c$ in cytosolic extracts and particulated extracts (pellet) was detected by Western blot in control cultures (C) and cultures treated for 6 and $24 \mathrm{~h}$ with $1 \mu \mathrm{mol} / / \mathrm{ISTS}$. (b) Upper panel: immunodetection of cleaved caspase- $3(\cong 17 \mathrm{kDa})$ in total protein extracts from the same cultures as in (a). Lower panel: immunodetection of caspase-3specific cleavage of fodrin $(\cong 120 \mathrm{kDa})$ in the same protein extracts as in the upper panel. (c) Caspase-3 activity was measured as the production of the afcDEVD.CHO fluorogenic cleavage product in extracts from control cultures (c), and cultures treated $24 \mathrm{~h}$ with $1 \mu \mathrm{mol} / / \mathrm{STS}$ (STS), and $1 \mu \mathrm{mol} / \mathrm{l} \mathrm{STS}$ plus $50 \mu \mathrm{mol} / \mathrm{l}$ of the caspase-3 inhibitor z-DEVD.fmk (STS + C3i). Data are representative results from three independent experiments

a time-dependent cleavage of caspase- 3 and fodrin, which is cleaved by caspase-3 rendering a fragment of $120 \mathrm{kDa}$. These effects were maximal at $24 \mathrm{~h}$ (Figure $4 \mathrm{~b}$ ). Caspase-3 cleavage in cardiomyocytes was faint and correlated with DNA laddering (Figure 3c), but neither with the number of dead cells nor the amount of cytosolic cytochrome $c$. Caspase-3-like activity, as determined by the cleavage of its specific fluorogenic substrate acetyl-Asp[OMe]-Glu[ome]Val-Asp[ome]-7-amino-4-trifluoromethylcoumarin (Ac-DEVD.afc) in vitro in cell lysates, increased after $24 \mathrm{~h}$ of STS treatment in endothelial cells but not in cardiomyocytes (Figure 4c). These results indicate that interruption of apoptosis occurred in cardiomyocytes after cytochrome $c$ translocation, but before caspase-3 activation.

\section{Cardiomyocyte resistance to the execution of the mitochondrial apoptotic program coincides with the deficiency in Apaf-1}

Since activation of caspase- 3 by the mitochondrial pathway implies assembly of the apoptosome ${ }^{23}$ incomplete formation of this complex could account for cytochrome $c$ translocation without activation of caspase-3. As caspase-9 is present in cardiomyocytes, ${ }^{24}$ we analyzed the presence of Apaf-1 as a major regulator of apoptosome activity. In contrast to endothelium, immunoreactive Apaf-1 was undetectable in Western blots of total cell lysates of rat primary cardiomyocyte cultures using an antibody raised against rat Apaf-1 (Figure 5). In addition, Apaf-1 was present at high levels in primary cultures of rat heart fibroblasts and rat aorta-derived vascular smooth muscle cells (data not shown). These data suggested that lack of Apaf-1 expression could be a cardiomyocytespecific strategy to avoid completion of apoptosis by the mitochondrial pathway.

\section{Restoration of Apaf-1 expression renders cardiomyocytes sensitive to STS-induced apoptosis}

Taken together, the above-presented data pointed to Apaf-1 deficiency as the major cause of cardiomyocyte resistance to apoptosis driven by the mitochondrial pathway. In order to test this hypothesis, we performed transient transfection of cardiomyocyte primary cultures with a plasmid encoding for the Apaf- $1 X_{L}$ isoform. ${ }^{25}$ These cultures were submitted to STS treatment and the occurrence of nuclear fragmentation as an indicator of cardiomyocyte apoptosis was investigated. Indeed, overexpression of Apaf-1 induced a three-fold increase in cardiomyocytes with fragmented nucleus (Figure 6) compared to control cultures transfected with empty vector. Treatment with $1 \mu \mathrm{mol} / / \mathrm{STS}$ of cell cultures overexpressing Apaf-1 further increased cardiomyocyte nuclear fragmentation up to seven-fold. In addition, coexpression of the antiapoptotic protein $\mathrm{Bcl}-\mathrm{X}_{\mathrm{L}}$ attenuated the effect of Apaf-1 (Figure 6), therefore suggesting the participa-

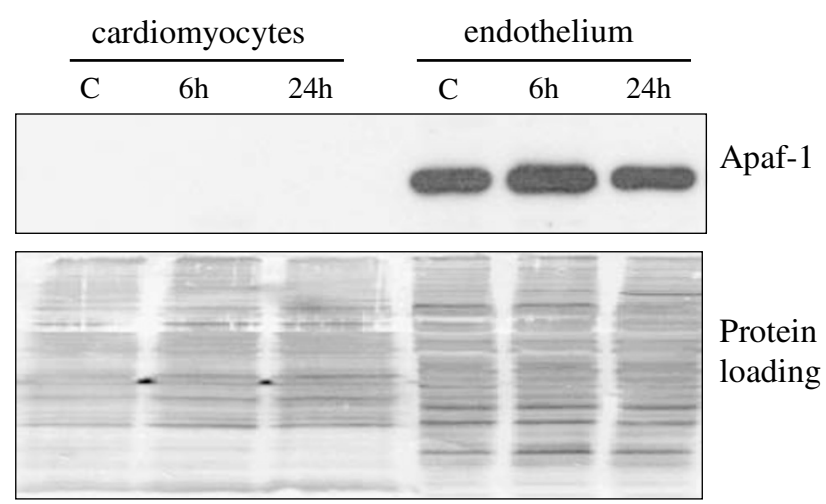

Figure 5 Primary postnatal cardiomyocytes do not express immunoreactive Apaf-1. Western blot detection of Apaf-1 in $30 \mu \mathrm{g}$ of cardiomyocyte and endothelial protein extracts from control cultures (C) and cultures treated for 6 and $24 \mathrm{~h}$ with $1 \mu \mathrm{mol} / \mathrm{I}$ STS. Representative image from three independent experiments 


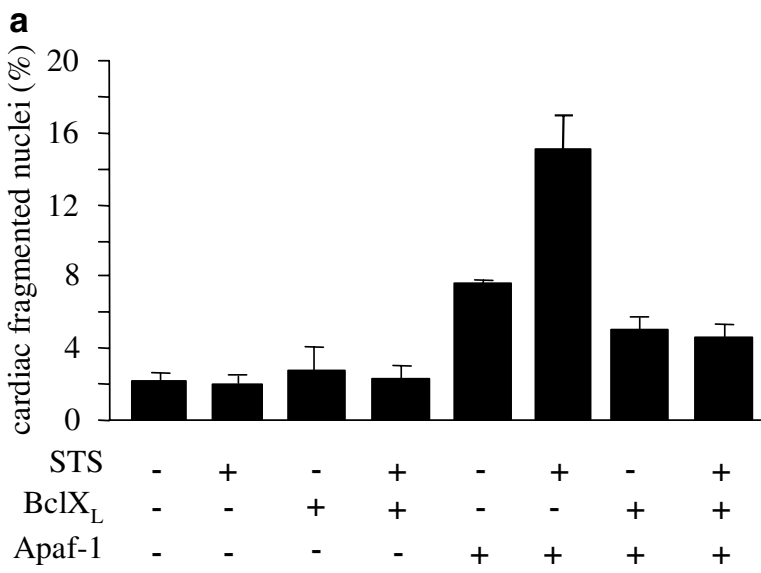

b

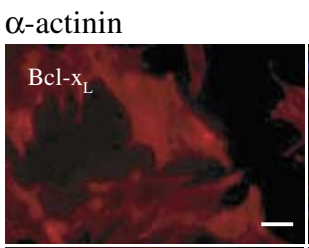

nuclei

EGFP

overlay
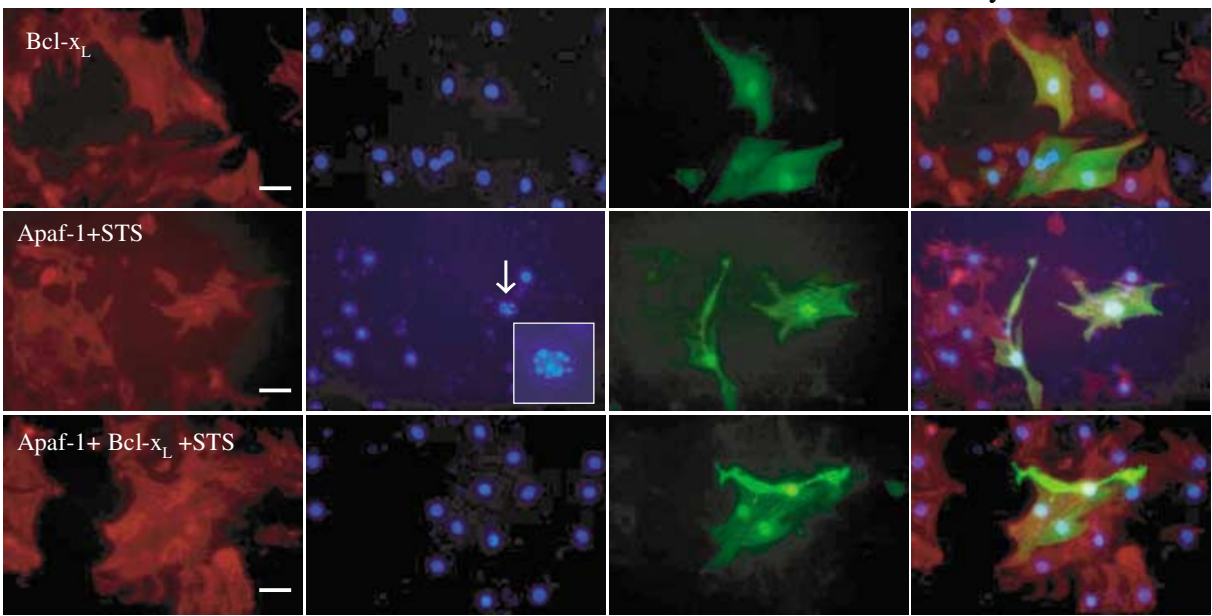

Figure 6 Transient expression of Apaf-1 renders postnatal cardiomyocytes susceptible to undergo mitochondrial-driven apoptosis. (a) Cardiac fragmented nuclei were counted in transiently transfected cardiomyocyte primary cultures as described in Methods section. STS was added $24 \mathrm{~h}$ after transfection at a final concentration of $1 \mu \mathrm{mol} / \mathrm{l}$ for $24 \mathrm{~h}$. Counting was done after $\alpha$-actinin immunodetection and bis-benzimide nuclear staining made in parallel in STS-treated or untreated wells. Data are expressed as cardiac-fragmented nuclei per 100 cardiac nuclei in cells expressing EGFP (mean \pm S.E.M. of three experiments made in duplicate). (b) Representative fluorescent photomicrographs of transiently transfected cardiomyocyte cultures used in (a). Inset: magnification image of the apoptotic nucleus. Bar, $50 \mu \mathrm{m}$

tion of the mitochondrial pathway in the Apaf-1-mediated nuclear fragmentation. These data indicate that when cardiomyocytes express Apaf-1, full canonical cytochrome $c$-driven apoptosis takes place, and confirms the significant role of Apaf-1 deficiency in myocardial resistance to apoptosis induced by the release of mitochondrial cytochrome $c$.

\section{Cardiomyocytes develop canonical apoptosis after serum deprivation and glucose metabolism inhibition}

STS did not trigger caspase-3 processing and type-2 nuclear fragmentation in cardiomyocytes. However, the same STS doses induced full apoptosis phenotype in contaminant nonmyocardial cells (Figure $7 \mathrm{a}$, upper and middle panels). To test whether myocardial cells were constitutively resistant to undergo canonical apoptosis, we subjected cardiomyocyte cultures to serum and glucose deprivation. Recently, Chao et al. have demonstrated that neonatal cardiomyocyte apoptosis induced by serum deprivation could be arrested by adenoviral delivery of dominant-negative FADD, pointing to the decisive role of death receptor/caspase-8-pathway in serum deprivation-induced apoptosis. ${ }^{16}$ Furthermore, although the involvement of the mitochondrial pathway has been suggested by other authors, ${ }^{20}$ their data could not rule out the relevant role of the extrinsic pathway.

In our experimental model, nuclear fragmentation occurred in cardiomyocytes cultured in serum-free, glucose-free medium in the presence of $1 \mathrm{mmol} / \mathrm{l} 2$-deoxy-D-glucose (Figure 7a, bottom row), and was blocked by the addition of $100 \mu \mathrm{mol} / \mathrm{l}$ of the specific caspase-8 inhibitor benzyloxycarbonyl-Ile-Glu[OMe]-Thr-Asp[OMe]-fluoromethylketone (z-IETD.fmk) (Figure 7b). Therefore, these data are in concordance with other works that indicate a major role of the extrinsic pathway in cardiomyocyte apoptosis induced by 


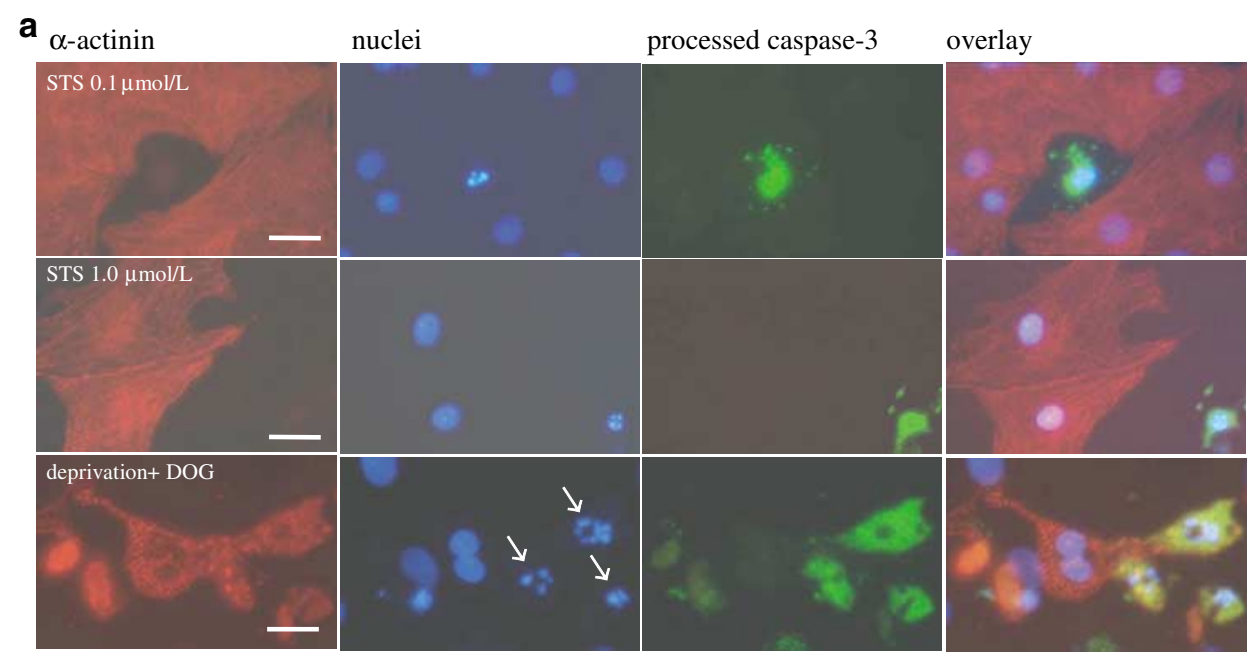

b

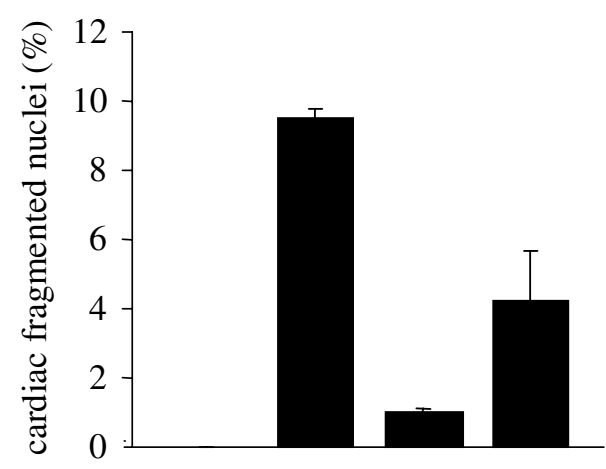

$\begin{array}{rcccc}\text { Deprivation } & + & + & + & + \\ \text { 2-deoxy-glucose } & - & + & + & + \\ \text { caspase-8 inhibitor } & - & - & + & - \\ \text { caspase-3 inhibitor } & - & - & - & +\end{array}$

Figure 7 Cardiomyocytes undergo caspase-8-dependent full apoptotic phenotype during serum deprivation and glucose metabolism inhibition. (a) Fluorescence photomicrographs of primary cultures of rat neonatal cardiomyocytes treated during $24 \mathrm{~h}$ with 0.1 and $1.0 \mu \mathrm{mol} / \mathrm{I}$ STS (upper and middle rows), or cultured in medium without serum and glucose in the presence of $1 \mathrm{mmol} / \mathrm{l} 2$-deoxy-D-glucose (DOG) (lower row). Cardiomyocytes were stained by immunocytochemistry with a cardiacspecific $\alpha$-actinin antibody (red); nuclear chromatin was stained with bis-benzimide dye (blue), and cleaved caspase-3 was immunodetected with a specific antibody (green). Arrows point to cardiac-fragmented nuclei. STS treatments and deprivation were performed in parallel in dishes coming from the same cultures. Images shown are representative of three independent experiments. Bar, $50 \mu \mathrm{m}$. (b) Cardiac-fragmented nuclei were counted after actinin immunodetection and nuclear staining in dishes coming from the same cultures as in (a), after $24 \mathrm{~h}$ of deprivation (medium without serum and glucose) with or without $1 \mathrm{mmol} / / \mathrm{DOG}, 100 \mu \mathrm{mol} / \mathrm{I}$ z-IETD.fmk (caspase-8 inhibitor), or $100 \mu \mathrm{mol} / \mathrm{I}$ z-DEVD.fmk (caspase-3 inhibitor). Data are expressed as mean \pm S.E.M. of cardiac-fragmented nuclei percentage in three independent experiments

serum and glucose deprivation. Thus, upon stimulation of the extrinsic death pathway, cardiac myocytes could undergo canonical apoptosis.

\section{Discussion}

Loss of myocardial cell mass cannot be counterbalanced by cardiomyocyte renewal ${ }^{26}$ and has been found to correlate with a bad outcome during the course of myocardial disease. Although myocardial cell loss has traditionally been attributed to necrosis, the contribution of apoptosis to cardiac disease is beginning to be unveiled. ${ }^{4,6,27,28}$

In the present work, we show that rat postnatal cardiomyocytes are resistant to STS-induced apoptosis, which is driven by the mitochondrial pathway through a mechanism involving proapoptotic Bcl2-family members Bax and Bak. ${ }^{15}$ In spite of the incomplete apoptosis phenotype observed in cardiomyocytes, a significant part of the cells in our myocardial cultures died after STS treatment. Apoptosis of contaminant fibroblasts and endothelium, which express Apaf-1, could account, at least in part, for the observed cell death. We can also hypothesize that a small population of cardiomyocytes developed apoptosis after STS treatment by an Apaf-1independent pathway. In fact, it has previously been reported that STS induces type-2 nuclear morphology and cell death in embryonic stem (ES) cells expressing Apaf- 1 and that, after ablation of the Apaf-1 gene, STS does not induce further nuclear degradation but still causes cell death, although at a much lesser extent. ${ }^{29}$ 
Cardiomyocytes treated with STS underwent slight cellular shrinking and cytochrome $c$ translocation to the cytosol, but showed neither caspase-3 activation nor nuclear fragmentation. This suggests the existence of antiapoptotic mechanisms acting downstream of cytochrome $c$ release and upstream of the execution phase of apoptosis. These observations appear to be at variance with previously published works suggesting the relevant role of the mitochondrial pathway in cardiomyocyte apoptosis. Indeed, cytochrome $c$ is released during hypoxia of neonatal ${ }^{21}$ and adult cardiomyocytes. ${ }^{30}$ Cytochrome $c$ release and DNA fragmentation have been shown to occur in cultured neonatal cardiomyocytes under hypoxia during inhibition of glucose metabolism ${ }^{21}$ and during serum and glucose deprivation. ${ }^{20}$ However, the lack of data on the activation of the extrinsic pathway and a more in-depth analysis of the mitochondrial pathway do not allow to know for the determination of whether cytochrom $c$ translocation is directly involved in the final apoptotic phenotype.

In this paper, we describe that nuclear condensation induced in cardiomyocytes by serum and glucose deprivation was suppressed by blocking the extrinsic apoptotic pathway with the specific caspase-8 inhibitor z.IETD.fmk. Although cytochrome $c$ has been shown to be released in adult cardiomyocytes subjected to oxidative stress, ${ }^{31}$ the activity of executioner caspases was not measured and apoptotic cells were defined as cells exposing phosphatidylserine in the outer outleaf of the cytosolic membrane, an early apoptotic event not directly related to the execution phase of the apoptotic process. ${ }^{32}$ Finally, release of cytochrome $c$ has been detected ex vivo in isolated whole rat hearts subjected to ischemia-reperfusion injury. ${ }^{8}$ However, although processing of caspase- 8 and caspase- 9 was detected in tissue slices immunostained with specific antibodies against the cleaved forms, addition of z-LEHD.fmk, which was used as an inhibitor of caspase-9, did not clearly change the number of Tdtmediated dUTP nick end-labeling (TUNEL)-positive cardiomyocytes. ${ }^{8}$ In fact, it has been reported that caspase- 9 activity does not rely on structural processing but on the formation of the apoptosome. ${ }^{33}$ In addition, recent evidence shows that caspase- 9 processing could allow for binding to the inhibitor of apoptosis protein XIAP, suggesting that cleavage may instead have an inhibitory effect. ${ }^{34}$ The relevance of cytochrome $c$ release for cardiomyocyte apoptosis has always been proposed in complex experimental situations, under the assumption that downstream apoptotic machinery was present in myocardial cells. ${ }^{30}$ On the contrary, our results are in agreement with a recent report showing that the release of cytochrome $c$ was not correlated with the activation of caspase- 3 in samples of failing human hearts. ${ }^{7}$

In the present work, we have shown that Apaf- 1 was absent in postnatal cardiomyocytes. This event could explain the lack of caspase- 3 activation and nuclear fragmentation observed despite cytochrome $c$ release. In our cultures, Apaf-1 deficiency was exclusive of cardiomyocytes, due to the fact that endothelium, cardiac fibroblasts and vascular smooth muscle cells expressed this protein. In fact, Apaf-1 gene repression has been described in tumor cell types resistant to drug-induced apoptosis. ${ }^{35,36}$ There is also evidence that supports that Apaf-1 expression could be lacking in skeletal myotubes ${ }^{37}$ and adult cortical neurons. ${ }^{38}$ However, although the latter work establishes a correlation between the expression of Apaf-1, the level of neuron maturation and the resistance to apoptosis, it does not have a functional approach. We report that transient expression of Apaf-1 in cardiomyocytes increased their susceptibility to undergo mitochondria-driven apoptosis. This effect was inhibited by antiapoptotic $\mathrm{Bcl}-2$-related protein, $\mathrm{Bcl}-\mathrm{X}_{\mathrm{L}}$, further supporting the idea that lack of Apaf-1 expression prevents completion of cytochrome $c$-driven apoptosis in terminally differentiated myocardial cells.

We have demonstrated that cardiomyocytes are capable of arresting the apoptotic program when it occurs through the mitochondrial pathway, but they are still susceptible to apoptosis when induced by activation of death receptors. Our results are in agreement with works showing that cardiomyocyte apoptosis courses by the extrinsic pathway in experimental models of different types of heart disease. ${ }^{16}$ Our work also agrees with the relevant role of the extrinsic pathway of apoptosis in the formation of the heart during embryogenesis. Indeed, morphologic alterations in the heart take place during embryogenesis in mice deficient for proteins involved in the extrinsic pathway (FADD, caspase-8, cFLIP), but not in null mice for proteins acting in the apoptotic mitochondrial pathway. ${ }^{39}$

In conclusion, we report that in postnatal rat cardiomyocytes, the release of cytochrome $c$ did not induce the activation of executioner caspases and nuclear fragmentation. We have also shown that the myocardial cells did not express Apaf-1, and that transient expression of this protein rendered cardiomyocytes prone to develop full canonic apoptosis upon stimulation of the mitochondrial pathway. In contrast, cardiomyocytes underwent apoptosis through the extrinsic pathway during serum deprivation and glucose metabolism inhibition. Our hypothesis is that lack of Apaf-1 is a mechanism developed by differentiated, postmitotic cardiomyocytes to block cytochrome $c$-driven apoptosis before entering the irreversible execution phase.

\section{Material and Methods}

\section{Cell cultures and treatments}

We obtained neonatal cardiomyocytes as described by Pelliux et al. $^{40}$ from the heart of 2-day-old Sprague-Dawley rat after digestion with type-2 collagenase (Worthington, Lakewood, NJ, USA). We used a two-round preplating in order to deplete cardiomyocyte culture of nonmyocardial cells. Cells were plated at a density of $10^{3}$ cells $/ \mathrm{mm}^{2}$ in $1 \mathrm{~g} / \mathrm{l}$ gelatin-coated FALCON polystyrene dishes (Becton Dickinson, Palo Alto, CA, USA) and NUNCLON four-well plates (NUNC, Denmark). The medium used was M199:DMEM 1:3 (SIGMA-Aldrich España, Alcobendas, Spain), $\mathrm{pH} 7.2$ with $7.2 \mathrm{mmol} / \mathrm{l}$ glucose, $10 \%$ horse serum and $5 \%$ fetal calf serum (Gibco BRL/Izasa, Spain). Cardiomyocyte purity was checked by immunocytochemistry with a cardiac sarcomeric $\alpha$-actinin monoclonal antibody (clone EA-53, SIGMA, St. Louis, MO, USA), and was found to be higher than $90 \%$ after $24 \mathrm{~h}$ in vitro. Deprivation was initiated after $24 \mathrm{~h}$ of plating, by culturing cells in DMEM minimal medium without serum and glucose (SIGMA), in the 
presence of $1 \mathrm{mmol} / \mathrm{l} 2$-deoxy-D-glucose (SIGMA). We added caspase-3 inhibitor z-DEVD.fmk and caspase-8 inhibitor zIETD.fmk (Enzyme System Products, Livermore, CA, USA) at $100 \mu \mathrm{mol} / \mathrm{l}$ when indicated.

Cow pulmonary artery endothelial (CPAE) cell line was purchased from the European Cell Collection (ECACC, UK). We cultured CPAE cells in EMEM-1\% nonessential aminoacids (SIGMA) and $20 \%$ FBS. STS (SIGMA) was added to the culture medium at the concentrations and times described in the figures.

\section{Quantification of cell death}

Detection of cell death was performed by the trypan blueexclusion assay after drug treatment for the times and concentrations described in the figures. Data are expressed as percentage of cell death in treated dishes versus equally loaded control dishes at time zero. Cell death for each experimental condition was measured in duplicate in three independent experiments.

\section{DNA integrity assessment}

Chromatin morphology was checked out by fluorescence microscopy after DNA staining with $0.5 \mathrm{mg} / \mathrm{l}$. bis-Benzimide dye (Hoechst 33258) in cells previously fixed with $4 \%$ paraformaldehyde (PFA) (SIGMA) in Phosphatebuffered saline(PBS). DNA fragmentation was assessed by conventional agarose-gel electrophoresis as previously reported. $^{41}$

\section{DEVD-directed caspase activity}

Caspase-3-like activity was measured as previously described. ${ }^{42}$ Cells were treated $24 \mathrm{~h}$ after plating with $1 \mu \mathrm{mol} / \mathrm{l} \mathrm{STS}$ for 24 hours, in the presence or absence of $100 \mu \mathrm{mol} / / \mathrm{z}$-DEVD-fmk. Cells were lysed and protein concentration in the lysates was measured by the Bradford assay (BioRad, Alcobendas, Spain). Equal loads of protein were mixed with the fluorogenic substrate Ac-DEVD-afc at $50 \mu \mathrm{M}$ (Enzyme Systems Products) in 96-well plates that were incubated at $37^{\circ} \mathrm{C}$ and fluorescence was read at intervals of $1 \mathrm{~h}$ during the next $6 \mathrm{~h}$ in a Bio-tek FL 600 fluorimeter (Izasa, Madrid, Spain), with excitation filter set at $360 \mathrm{~nm}$ and emission filter at $530 \mathrm{~nm}$. Data obtained for different experimental conditions were compared within the linear phase of absorbance increase.

\section{Preparation of cytosolic extracts}

Cytosolic fractions were obtained at the end of the treatments, in order to detect cytochrome $c$ release from the mitochondria, by mixing pelleted cells in a buffer without detergent containing $220 \mathrm{mmol} / \mathrm{l}$ manitol (SIGMA). Cells were incubated on ice for $15 \mathrm{~min}$ and subjected to a serial centrifugation protocol ${ }^{43}$ with some modifications. ${ }^{41}$ Cytochrome $c$ was measured in the cytosolic extract (supernatant) and the particulate fraction (pellet).

\section{Protein extraction, Western blotting and immunocytochemistry}

Cells were detached from the culture dishes, pelleted and washed twice with ice-cold PBS. After lysis in RIPA buffer, cells were centrifuged and the supernatant was used as whole-protein cell lysate. Protein concentration was then measured in total and cytosolic extracts by the Lowry assay. SDS-PAGE electrophoresis was performed and protein was electrotransferred to Immobilon-P filters (Millipore, Bedford, MA, USA) and reacted with the adequate primary antibodies. Immunoblots were exposed to an appropriate secondary peroxidase-conjugated antibody and developed with the SuperSignal Substrate (Pierce/Cultek, Madrid, Spain). Fluorescence immunocytochemistry of $\alpha$-actinin and processed caspase-3 was performed in 4\% PFA-fixed cultures permeabilized with $0.1 \%$ Triton-X (SIGMA) in PBS with $5 \%$ horse serum (SIGMA), mounted with Vectashield (Vector Laboratories, Burlingame, CA, USA) and visualized with an Olympus IX70 vertical epifluorescence phase-contrast microscope. Primary antibodies used were anti-human cytochrome $c$ (BD-Pharmingen, Palo Alto, CA, USA); anti-human processed caspase-3 (Cell Signaling, Beverly, MA, USA); antihuman $\alpha$-fodrin and anti-rat Apaf-1 ( $\mathrm{N}$-terminus) (Chemicon, Temecula, CA, USA).

\section{Apaf-1 transfection}

Full-length Apaf-1 from 293 T cells containing an 11-aminoacid $\mathrm{NH}_{2}$-terminal insert and an extra WD repeat cloned in pCDNA3 vector was generously supplied by Gabriel Nuñez (University of Michigan Medical School). We amplified this construct in E. coli Stbl2 strain (Invitrogen, Leek, The Netherlands) at $30^{\circ} \mathrm{C}$ to avoid spontaneous mutations. Cardiomyocytes were transfected $3 \mathrm{~h}$ after plating by the LipofectAMINE ${ }^{\circledR}$ method (Invitrogen) with $0.5 \mu \mathrm{g}$ of pcDNA3Apaf- $1 \mathrm{X}_{\mathrm{L}}, \mathrm{Bcl}-\mathrm{X}_{\mathrm{L}}{ }^{41}$ or empty vector, plus $0.5 \mu \mathrm{g}$ of empty vector and $0.3 \mu \mathrm{g}$ of pcDNA3-enhanced green fluorescent protein (EGFP) per $10^{5}$ cells. Cotransfection of Apaf- 1 and $\mathrm{Bcl}-\mathrm{X}_{\mathrm{L}}$ was achieved by using a mixture of $0.5 \mu \mathrm{g}$ of both the plasmids plus $0.3 \mu \mathrm{g}$ of pcDNA3-EGFP. Transfected cultures were treated $24 \mathrm{~h}$ later with STS at a final concentration of $1 \mu \mathrm{mol} / /$ for $24 \mathrm{~h}$. Nuclear morphology was checked in parallel in STS-treated and untreated cultures $48 \mathrm{~h}$ after transfection. Cardiac-fragmented nuclei were counted after bis-benzimide staining in $\alpha$-actinin-positive cells expressing EGFP. Data shown are the mean of three independent experiments made in duplicate.

\section{Acknowledgements}

We thank Gabriel Nuñez for the pcDNA3-Apaf-1XL construct. The present work has been partially supported by grants from the Fundació Marató de TV3 to JX Comella and M Ballester, and the Fondo de Investigaciones Sanitarias (01/3023 and PI020116 to D Sanchis and PI020051 to JX Comella). D Sanchis has been partially supported by a postdoctoral Grant from the Generalitat de Catalunya and by the Fondo de Investigaciones Sanitarias (01/3023). M Mayorga is supported by a Young Researcher Award from the Generalitat de Catalunya to JX Comella. We thank Neil Goodman for proof-reading and editing the manuscript. 


\section{References}

1. Olivetti G, Abbi R, Quaini F, Kajstura J, Cheng W, Nitahara JA, Quaini E, Di Loreto C, Beltrami CA, Krajewski S, Reed JC and Anversa P (1997) Apoptosis in the failing human heart. N. Engl. J. Med. 336: 1131-1141

2. Narula J, Pandey $P$, Arbustini $E$, Haider $N$, Narula N, Kolodgie FD, Dal Bello B, Semigran MJ, Bielsa-Masdeu A, Dec GW, Israels S, Ballester M, Virmani R, Saxena S and Kharbanda S (1999) Apoptosis in heart failure: release of cytochrome $c$ from mitochondria and activation of caspase-3 in human cardiomyopathy. Proc. Natl. Acad. Sci. USA 96: 8144-8149

3. Narula J, Acio ER, Narula N, Samuels LE, Fyfe B, Wood D, Fitzpatrick JM, Raghunath PN, Tomaszewski JE, Kelly C, Steinmetz N, Green A, Tait JF, Leppo J, Blankenberg FG, Jain D and Strauss HW (2001) Annexin-V imaging for noninvasive detection of cardiac allograft rejection. Nat. Med. 7: $1347-1352$

4. Gonzalez A, Lopez B, Ravassa S, Querejeta R, Larman M, Diez J and Fortuno MA (2002) Stimulation of cardiac apoptosis in essential hypertension: potential role of angiotensin II. Hypertension 39: 75-80

5. Anversa P, Leri A, Kajstura J and Nadal-Ginard B (2002) Myocyte growth and cardiac repair. J. Mol. Cell. Cardiol. 34: 91-105

6. Olivetti G, Quaini F, Sala R, Lagrasta C, Corradi D, Bonacina E, Gambert SR, Cigola $E$ and Anversa $P$ (1996) Acute myocardial infarction in humans is associated with activation of programmed myocyte cell death in the surviving portion of the heart. J. Mol. Cell. Cardiol. 28: 2005-2016

7. Scheubel RJ, Bartling B, Simm A, Silber RE, Drogaris K, Darmer D and Holtz J (2002) Apoptotic pathway activation from mitochondria and death receptors without caspase-3 cleavage in failing human myocardium: fragile balance of myocyte survival? J. Am. Coll. Cardiol. 39: 481-488

8. Scarabelli TM, Stephanou A, Pasini E, Comini L, Raddino R, Knight RA and Latchman DS (2002) Different signaling pathways induce apoptosis in endothelial cells and cardiac myocytes during ischemia/reperfusion injury. Circ. Res. 90: 745-748

9. Nicholson DW, Ali A, Thornberry NA, Vaillancourt JP, Ding CK, Gallant M, Gareau Y, Griffin PR, Labelle M and Lazebnik YA, et al. (1995) Identification and inhibition of the ICE/CED-3 protease necessary for mammalian apoptosis. Nature 376: 37-43

10. Widmann C, Gibson S and Johnson GL (1998) Caspase-dependent cleavage of signaling proteins during apoptosis. A turn-off mechanism for anti-apoptotic signals. J. Biol. Chem. 273: 7141-7147

11. Liu X, Li P, Widlak P, Zou H, Luo X, Garrard WT and Wang X (1998) The 40-kDa subunit of DNA fragmentation factor induces DNA fragmentation and chromatin condensation during apoptosis. Proc. Natl. Acad. Sci. USA 95: 8461-8466

12. Liu X, Kim CN, Yang J, Jemmerson R and Wang X (1996) Induction of apoptotic program in cell-free extracts: requirement for dATP and cytochrome c. Cell $86: 147-157$

13. Du C, Fang M, Li Y, Li L and Wang X (2000) Smac, a mitochondrial protein that promotes cytochrome $c$-dependent caspase activation by eliminating IAP inhibition. Cell 102: 33-42

14. Bertrand R, Solary E, O'Connor P, Kohn KW and Pommier Y (1994) Induction of a common pathway of apoptosis by staurosporine. Exp. Cell. Res. 211: 314321

15. Wei MC, Zong WX, Cheng EH, Lindsten T, Panoutsakopoulou V, Ross AJ, Roth KA, MacGregor GR, Thompson CB and Korsmeyer SJ (2001) Proapoptotic Bax and Bak: a requisite gateway to mitochondrial dysfunction and death. Science 292: 727-730

16. Chao W, Shen Y, Li L and Rosenzweig A (2002) Importance of FADD signaling in serum-deprivation- and hypoxia-induced cardiomyocyte apoptosis. J. Biol. Chem. 277: 31639-31645

17. Li K, Li Y, Shelton JM, Richardson JA, Spencer E, Chen ZJ, Wang $X$ and Williams RS (2000) Cytochrome $c$ deficiency causes embryonic lethality and attenuates stress-induced apoptosis. Cell 101: 389-399

18. Varfolomeev EE, Schuchmann M, Luria V, Chiannilkulchai N, Beckmann JS, Mett IL, Rebrikov D, Brodianski VM, Kemper OC, Kollet O, Lapidot T, Soffer D, Sobe T, Avraham KB, Goncharov T, Holtmann H, Lonai P and Wallach D (1998) Targeted disruption of the mouse caspase 8 gene ablates cell death induction by the TNF receptors, Fas/Apo1, and DR3 and is lethal prenatally. Immunity 9: 267-276
19. Yang J, Liu X, Bhalla K, Kim CN, Ibrado AM, Cai J, Peng TI, Jones DP and Wang X (1997) Prevention of apoptosis by Bcl-2: release of cytochrome $c$ from mitochondria blocked. Science 275: 1129-1132

20. Bialik S, Cryns VL, Drincic A, Miyata S, Wollowick AL, Srinivasan A and Kitsis RN (1999) The mitochondrial apoptotic pathway is activated by serum and glucose deprivation in cardiac myocytes. Circ. Res. 85: 403-414

21. Malhotra R and Brosius FC (1999) Glucose uptake and glycolysis reduce hypoxia-induced apoptosis in cultured neonatal rat cardiac myocytes. J. Biol. Chem. 274: 12567-12575

22. Jänicke RU, Ng P, Sprengart ML and Porter AG (1998) Caspase-3 is required for alpha-fodrin cleavage but dispensable for cleavage of other death substrates in apoptosis. J. Biol. Chem. 273: 15540-15545

23. Li P, Nijhawan D, Budihardjo I, Srinivasula SM, Ahmad M, Alnemri ES and Wang X (1997) Cytochrome $C$ and dATP-dependent formation of Apaf-1/caspase-9 complex initiates an apoptotic protease cascade. Cell 91: 479-489

24. Stephanou A, Brar B, Liao Z, Scarabelli T, Knight RA and Latchman DS (2001) Distinct initiator caspases are required for the induction of apoptosis in cardiac myocytes during ischaemia versus reperfusion injury. Cell Death Differ. 8: 434-435

25. Benedict MA, Hu Y, Inohara N and Nunez G (2000) Expression and functional analysis of Apaf-1 isoforms. J. Biol. Chem. 275: 8461-8468

26. Anversa $P$ and Nadal-Ginard $B$ (2002) Myocyte renewal and ventricular remodeling. Nature 415: 240-243

27. Narula J, Haider N, Virmani R, DiSalvo TG, Kolodgie FD, Hajjar RJ, Schmidt U, Semigran MJ, Dec GW and Khaw BA (1996) Apoptosis in myocytes in end stage heart failure. N. Engl. J. Med. 335: 1182-1189

28. Gill C, Mestril R and Samali A (2002) Losing heart: the role of apoptosis in heart disease - a novel therapeutic target? FASEB J. 16: 135-146

29. Haraguchi M, Torii S, Matsuzawa S, Xie Z, Kitada S, Krajewski S, Yoshida H, Mak TW and Reed JC (2002) Apoptotic protease activating factor (Apaf-1)independent cell death suppression by Bcl-2. J. Exp. Med. 191: 1709-1720

30. De Moissac D, Gurevich RM, Zheng H, Singal PK and Kirshenbaum LA (2000) Caspase activation and mitochondrial cytochrome $c$ release during hypoxiamediated apoptosis of adult ventricular myocytes. J. Mol. Cell. Cardiol. 32: 5363

31. Aoki H, Kang PM, Hampe J, Yoshimura K, Noma T, Matsuzaki M and Izumo S (2002) Direct activation of mitochondrial apoptosis machinery by c-Jun Nterminal kinase in adult cardiac myocytes. J. Biol. Chem. 277: 10244-10250

32. van Heerde WL, Robert-Offerman S, Dumont E, Hofstra L, Doevendans PA, Smits JF, Daemen MJ and Reutelingsperger CP (2000) Markers of apoptosis in cardiovascular tissues: focus on Annexin V. Cardiovasc. Res. 45: 549-559

33. Stennicke HR, Deveraux QL, Humke EW, Reed JC, Dixit VM and Salvesen GS (1999) Caspase-9 can be activated without proteolytic processing. J. Biol. Chem. 274: 8359-8362

34. Srinivasula SM, Hegde R, Saleh A, Datta P, Shiozaki E, Chai J, Lee RA, Robbins PD, Fernandes-Alnemri T, Shi $Y$ and Alnemri ES (2001) A conserved XIAP-interaction motif in caspase- 9 and SMAC/DIABLO regulates caspase activity and apoptosis. Nature 410: 112-116

35. Jia L, Srinivasula SM, Liu FT, Newland AC, Fernandes-Alnemri T, Alnemri ES and Kelsey SM (2001) Apaf-1 protein deficiency confers resistance to cytochrome c-dependent apoptosis in human leukemic cells. Blood 98: 414421

36. Soengas MS, Capodieci P, Polsky D, Mora J, Esteller M, Opitz-Araya X, McCombie R, Herman JG, Gerald WL, Lazebnik YA, Cordon-Cardo C and Lowe SW (2001) Inactivation of the apoptosis effector Apaf-1 in malignant melanoma. Nature 409: 207-211

37. Burgess DH, Svensson M, Dandrea T, Gronlund K, Hammarquist F, Orrenius S and Cotgreave IA (1999) Human skeletal muscle cytosols are refractory to cytochrome $c$-dependent activation of type-II caspases and lack Apaf-1. Cell Death Differ. 6: 256-261

38. Yakovlev AG, Ota K, Wang G, Movsesyan V, Bao WL, Yoshihara K and Faden Al (2001) Differential expression of apoptotic protease-activating factor-1 and caspase-3 genes and susceptibility to apoptosis during brain development and after traumatic brain injury. J. Neurosci. 21: 7439-7446

39. Joza N, Kroemer $G$ and Penninger JM. (2002) Genetic analysis of the mammalian cell death machinery. Trends Genet. 18: 142-149

40. Pellieux C, Sauthier T, Domenighetti A, Marsh DJ, Palmiter RD, Brunner HR and Pedrazzini T (2000) Neuropeptide Y (NPY) potentiates phenylephrine- 
induced mitogen-activated protein kinase activation in primary cardiomyocytes via NPY Y5 receptors. Proc. Natl. Acad. Sci. USA 97: 1595-1600

41. Yuste VJ, Sanchez-Lopez I, Sole C, Encinas M, Bayascas JR, Boix J and Comella JX (2002) The prevention of the staurosporine-induced apoptosis by $\mathrm{Bcl}-\mathrm{XL}$, but not by $\mathrm{Bcl}-2$ or caspase inhibitors, allows the extensive differentiation of human neuroblastoma cells. J. Neurochem. 80: 126-139

42. Yuste VJ, Bayascas JR, Llecha N, Sanchez-Lopez I, Boix J and Comella JX (2001) The absence of oligonucleosomal DNA fragmentation during apoptosis of IMR-5 neuroblastoma cells: disappearance of the caspase-activated DNase. J. Biol. Chem. 276: 22323-22331

43. Li X, Marani M, Mannucci R, Kinsey B, Andriani F, Nicoletti I, Denner L and Marcelli M (2001) Overexpression of BCL-X(L) underlies the molecular basis for resistance to staurosporine-induced apoptosis in PC-3 cells. Cancer Res. 61: 1699-1706 